\title{
Impact of a combined pulsed electric field (PEF) and enzymatic mash treatment on yield, fermentation behaviour and composition of white wine
}

\author{
T. Fauster ${ }^{1} \cdot$ C. Philipp ${ }^{2} \cdot$ K. Hanz ${ }^{1} \cdot$ R. Scheibelberger ${ }^{1} \cdot$ T. Teufl $^{1} \cdot$ S. Nauer ${ }^{2} \cdot$ H. Scheiblhofer ${ }^{2} \cdot$ H. Jaeger ${ }^{1}$
}

Received: 13 September 2019 / Revised: 17 December 2019 / Accepted: 21 December 2019 / Published online: 20 January 2020

(c) The Author(s) 2020

\begin{abstract}
The aim of this work was to study the combined application of a pulsed electric field (PEF) and an enzymatic treatment to white wine mash. The resulting impact of membrane permeabilisation by electroporation and pectin degradation by enzymes on fermentation behaviour and quality of white wine was assessed. The mash of two varieties, Traminer and Grüner Veltliner, was PEF treated ( 3 and $10 \mathrm{~kJ} / \mathrm{kg}$ ) using a continuous co-linear treatment chamber. Pectinases were added immediately afterwards and maceration was performed for 4 and $24 \mathrm{~h}$. Various physico-chemical parameters were analysed at different stages of the production process and the impact of the combined treatment on volatile compounds such as esters and terpenes was analysed by gas chromatography-mass spectrometry and a sensory panel in the final white wine after bottling and storage. Regardless of the PEF treatment intensity, the variety and the maceration time, the release of juice was not significantly influenced. For Traminer, the fermentation time was reduced through the enhanced extraction of nitrogen from 322 to $359 \mathrm{mg} / \mathrm{L}$ due to PEF treatment $(10 \mathrm{~kJ} / \mathrm{kg})$. The release of phenols which were localized in the pulp, were significantly more affected than phenols from the skin. Although the concentration of selective esters especially of the variety Traminer significantly increased, the sensory evaluation indicated no positive effect on the olfactory properties. Overall, the combination of PEF and enzyme pretreatment showed benefits in reducing the fermentation time and increasing the content of selective esters for Traminer.
\end{abstract}

Keywords Pulsed electric field · Enzymes · White wine production · Yield · Aroma profile

\section{Introduction}

The challenges of modern wine production are mostly related to economic aspects like juice yield and fermentation behaviour as well as quality parameters such as aroma profile and sensory attributes. Both aspects require the extraction of valuable ingredients from grape berries. Therefore, efficient cell permeabilisation by mechanical disruption and degradation of cell wall compounds like pectin is required $[1,2]$. It is well known that the quality of red and white

T. Fauster

thomas.fauster@boku.ac.at

1 Institute of Food Technology, University of Natural Resources and Life Sciences (BOKU), Muthgasse 18, 1190 Vienna, Austria

2 Federal College and Research Institute for Viticulture and Pomology (HBLAuBA), Klosterneuburg, Austria wines can be improved by extending the time of skin contact (maceration time). Whereas, by red wine production, the extraction of anthocyanins, polyphenols and volatile compounds is reached through the fermentation process on the skin (2-20 days), producers of white wines usually use enzymes to increase the juice yield and accelerate extraction of quality related components in less time (4-48 h) [3]. The commercial maceration enzymes are used for two different reasons: pectinases, cellulases and hemicellulases degrade hydrocolloids, which improves the juice yield and glycosidases break the connection of sugar-bonded aromatic compounds, thus increasing the extraction of volatile compounds of wines $[4,5]$. Especially essential aroma precursors, such as 1-hexanol, nerol, geraniol and benzene derivative are located in the skin of the grape berries [6-8]. Hence, the processing of "aromatic" grape varieties, like Muscat, Gewürztraminer and Riesling, which also usually contain higher amounts of pectin, require the addition of pectinases. Moreover, for a sufficient separation of lees prior 
to the fermentation, the usage of pectinases are necessary and common. Wenzel, Dittrich [9] determined that in many cases, musts with higher turbidity tend to the formation of negative aroma components during the fermentation process, such as $\mathrm{H}_{2} \mathrm{~S}$-like odours, which are related to rotten eggs.

In recent years, the usage of pulsed electric field (PEF) as an alternative for improving the juice recovery and extraction from various raw materials was frequently investigated and related benefits were described [10-12]. Thereby, unlike the application of enzymes, the enhanced extractability is related to the formation of pores in the cell membrane by electroporation. So far, the application of PEF pretreatment was mainly investigated for the production of red wines. Especially, aspects like fermentation behaviour, colour and the extraction of skin related components, such as polyphenols and anthocyanins, were studied [13-16]. The investigated parameters vary between the studies which make a direct comparison difficult. The applied field strength levels are generally lower than $1 \mathrm{kV} / \mathrm{cm}$. Lebovka et al. [17] suggested a field strength of 400-600 V/cm for a sufficient treatment of grapes by PEF. However, the applied energy input ranges between 0.4 up to $120 \mathrm{~kJ} / \mathrm{kg}[18,19]$.

López-Giral et al. [20] found an increase in the content of specific polyphenols such as gallic acid (24\%), caffeic acid (48\%) and rutin (141\%) after PEF pretreatment of red grapes of different varieties. A comparison of enzyme treatment and PEF treatment with regard to the impact on the extraction process was done by Donsì et al. [21] and revealed that for some of the investigated varieties, the enzyme treatment showed more pronounced effects. In contrast, Puértolas et al. [22] stated that the extraction of phenolic compounds from red grape mash after PEF treatment was more effective than the addition of enzymes.

Grimi et al. [23] reported that a PEF pretreatment $(E=400 \mathrm{~V} / \mathrm{cm} W \approx 15 \mathrm{~kJ} / \mathrm{kg}$ ) of chardonnay grapes without the use of enzymes and with no additional time of skin contact increased the release of juice at constant pressure (1.0 bar) during pressing from 67 to $75 \%$. Moreover, a $20 \%$ higher juice yield was achieved after PEF pretreatment $(E=750 \mathrm{~V} / \mathrm{cm} W \approx 20 \mathrm{~kJ} / \mathrm{kg}$ ) of white grapes, whereby during the pressing process $(t=45 \mathrm{~min})$ constant 5 bar were applied. Comuzzo et al. [24] describe a beneficial release of volatile compounds in white wine, such as terpenic and norisoprenoid glycosides by PEF $(E=1.5 \mathrm{kV} / \mathrm{cm} W=11$ and $22 \mathrm{~kJ} / \mathrm{kg}$ ). However, most of the analysed volatile compounds were below the olfactory threshold.

However, previous works only investigated the separate application of PEF and enzyme treatment for wine processing. Additionally, the effect of PEF on the extraction of polyphenols and volatile compounds was mainly described for red wines only. Only limited results about the impact of electric fields on the vinification process of white wines and quality related parameters, such as volatile compounds, are available [24]. Therefore, the two different mechanisms, mechanical cell disruption by PEF and degradation of cell components (pectin) by enzymes were combined and their potential to improve the modern white wine processing was investigated in this work. Different PEF intensities (3 and $10 \mathrm{~kJ} / \mathrm{kg}$ at $3 \mathrm{kV} / \mathrm{cm}$ ) and maceration times (4 and $24 \mathrm{~h}$ ) were compared regarding relevant parameters, like juice yield, fermentation behaviour, turbidity and general quality parameters including the content of phenols and volatile components, such as terpenes and esters.

\section{Material and methods}

\section{Raw material}

Grapes from Vitis vinifera L. var. Grüner Veltliner (GV) and Traminer (Tr) harvested in 2017 from Lower Austria were used. All samples from each variety were handpicked and selected on the same day. The grapes were harvested at the optimum ripening stage with regard to sugar content ( $\mathrm{KMW}$ ) and acidity and stored for $12 \mathrm{~h}$ at $2{ }^{\circ} \mathrm{C}$ to achieve a temperature homogeneity in all batches. The grape material was randomized and separated in batches of similar size before further processing.

\section{Pulsed electric field treatment and wine production}

Prior to the application of pulsed electric field (PEF) treatment, single grape lots $(\approx 30 \mathrm{~kg})$ were destemmed and crushed. The mash (electrical conductivity $2 \mathrm{mS} / \mathrm{cm}$ ) was pumped by an eccentric screw pump with a throughput of $440 \mathrm{~kg} / \mathrm{h}$ through a co-linear treatment chamber (diameter $50 \mathrm{~mm}$ ) consisting of three stainless steel electrodes (distance $43 \mathrm{~mm}$ ), with the central electrode connected to high voltage and the outer electrodes connected to ground. The used PEF generator (ScandiNova Systems, Sweden) provides rectangular pulses with a pulse duration of $3 \mu$ s. The PEF treatment parameters were selected in accordance to literature and preliminary tests in laboratory scale. Since a co-linear treatment chamber was used, the electric field strength is not homogeneously distributed. Hence, the average field strength was calculated based on Meneses et al. [25] and a value of $3 \mathrm{kV} / \mathrm{cm}$ was obtained and kept constant for all trials. The specific energy input $(3$ and $10 \mathrm{~kJ} /$ $\mathrm{kg}$ ) was adjusted in dependence of the electrical current by changing the frequency. A total treatment time of $170 \mu$ s and $502 \mu$ s resulted for the lower and higher energy input level. Voltage and electric current were controlled using a digital oscilloscope (TBS 1102B-EDU, Tektronix, US). To prevent further mechanical disruption of the grapes during pumping, tubes with an inner diameter of minimum $50 \mathrm{~mm}$ were used. Immediately after PEF treatment, $3 \mathrm{~g} / \mathrm{hL}$ pectolytic enzymes 
(novoclair, Novozyme, Denmark) and $50 \mathrm{mg} / \mathrm{L}$ Sulphur dioxide were added to both PEF pretreated and untreated control mash and 4 and $24 \mathrm{~h}$ time of skin contact at $15^{\circ} \mathrm{C}$ was realised. Pressing was realized in a small pneumatic press whereby the pressure regime was adapted to common industrial production conditions. Therefore, three consecutive steps were applied: (1) free juice release without additional pressure for $3 \mathrm{~min}$, (2) moderate increase of pressure up to 1.5 bar for $3 \mathrm{~min}$, (3) further pressure increase up to 2 bar for $3 \mathrm{~min}$. After $12 \mathrm{~h}$ of spontaneous settling with the addition of $140 \mathrm{mg} / \mathrm{L}$ bentonite, clarification using a cellulose-based additive (Trubex neu, Erbslöh, Germany) was done. For standardized fermentation conditions, commercial yeasts for wine making (1118, Erbslöh, Germany) were added and the fermentation took place at a constant temperature of $18{ }^{\circ} \mathrm{C}$. After completion of the fermentation, samples were centrifuged using a separator. For stabilization, $50 \mathrm{mg} / \mathrm{L}$ sulphur dioxide was added. Before bottling, wines were filtered, sulphur dioxide concentration was controlled and complemented to a concentration of $50 \mathrm{mg} / \mathrm{L}$. Bottles were closed with screw caps and stored at $12{ }^{\circ} \mathrm{C}$ throughout the storage period until sampling after 3 and 10 months.

\section{Juice yield}

For the expression of juice yield in dependency of pressing pressure, the pretreated mash was weighted before pressing and the released juice was measured separately after each pressing step. According to Mannozzi et al. [10], for the evaluation of the juice yield and the proportion $\left(Y_{x}\right)$ of each pressing step, Eq. 1 was used, whereby $m$ means the mass of juice and $x$ indicates the respective pressing step.

$Y_{x}=\frac{100}{\sum m} \times m_{x}$

\section{Turbidity of juice}

Turbidity was measured immediately after pressing using a nephelometer (Turb 430, WTW, Weilheim, Germany) and expressed as nephelometric turbidity units (NTU), which describe the concentration of suspended particles in the grape juice [26]. Before the measurement, samples were diluted fourfold which was taken into account for the calculation.

\section{Oenological parameters and fermentation behaviour}

During the fermentation process, the fermentation behaviour was determined by measuring the density with a portable density meter (DMA 35, Anton Paar, Austria). Furthermore, chemical parameters such as content of sugar $(\mathrm{g} / \mathrm{L})$, alcohol $(\% \mathrm{vol})$, total nitrogen $(\mathrm{mg} / \mathrm{L})$ and acids $(\mathrm{g} / \mathrm{L})$ were controlled periodically by FT-IR analyses, according to OIV/OENO Resolution 390/2010 using FOSS-WineScan (FT 120 Reference Manual, Foss, Hamburg, Germany).

\section{Polyphenol content}

Total polyphenol content (TPC) was determined after 10 months of storage using the FolinCiocalteu method according to Singleton et al. [27]. Therefore, $0.120 \mathrm{~mL}$ sample and $0.600 \mathrm{~mL}$ FolinCiocalteu reagent were mixed; after 2 min $0.960 \mathrm{~mL} \mathrm{Na}_{2} \mathrm{CO}_{3}$ (7.5\%) was added. After $5 \mathrm{~min}$ incubation at $50{ }^{\circ} \mathrm{C}$, the mixture was cooled to room temperature and absorbance was measured with a spectrophotometer (UV-1800, Shimadzu, Kyoto, Japan) at $760 \mathrm{~nm}$. For calibration, a standard curve $(0.01-0.10)$ with ferulic acid, was conducted. In addition, hydroxycinnamic acids were investigated by HPLC-method, according to Vrhovšek [28], with respect to the modification of Eder et al. [29] and Liszt et al. [30].

\section{Aroma profile-volatile components}

\section{Esters}

Selective esters were analysed 3 months after bottling using stable isotope dilution assay headspace solid-phase micro extraction gas chromatography-mass spectrometry (SIDAHS-SPME-GC-MS). An adapted analytical method based on the procedure described by Philipp et al. [31] and Philipp et al. [32] was used. Therefore, a 7890A GC system (Agilent technologies, Paolo Alto, CA, USA) equipped with a DB-5 capillary column $(60 \mathrm{~m} \times 0.25 \mathrm{~mm}, 0.25 \mu \mathrm{m}$; stationary phase 5\% dimethyl polysiloxane, 95\% phenyl polysiloxane), a CombiPal autosampler (CTC analytics, Zwingen, Switzerland) and a 5975C MS detector (Agilent) were used. For the measurement, $1 \mathrm{~mL}$ sample, $2 \mathrm{~mL}$ Milli-Q water and $10 \mu \mathrm{L}$ internal standard solution were mixed and transferred to a $20 \mathrm{~mL}$ head space vial containing $1 \mathrm{~g} \mathrm{NaCl}$ (Zeller Hohenems, Austria). The internal standard solution includes (d5)ethyl valerate, (d5)-ethyl hexanoate, (d5)-ethyl octanoate and (d5)-ethyl decanoate with an end concentration of $40 \mu \mathrm{g} / \mathrm{L}$. For the headspace solid-phase microextraction (HS-SPME), a polyacrylate fibre $(85 \mu \mathrm{m})$ from Sigma Aldrich, St. Louis, USA was used.

\section{Terpenes}

Selective free monoterpenes were analysed in the must before the fermentation started and after 3 months of storage by gas chromatography-mass spectrometry (GC/MS). The analytical procedure is based on the method described 
by Michlmayr et al. [33]. For the measurement, the same equipment as previously described for esters was used. For analysis, $5 \mathrm{~mL}$ of sample and $10 \mu \mathrm{L}$ internal standard 3,4-dimethylanisol, (Sigma Aldrich, St. Louis, USA), with an end concentration of $20 \mu \mathrm{g} / \mathrm{L}$ were mixed and combined in a headspace vial with $1.5 \mathrm{~g} \mathrm{NaCl}$ (Zeller Hohenems, Austria). A $100 \mu \mathrm{m}$ polydimethylsiloxane (PDMS) (SigmaAldrich, St. Louis, USA) was used for the headspace solidphase microextraction (HS-SPME) as sample application system. The concentration of the sesquiterpene, rotundone of the variety Grüner Veltliner was separately analysed 3 months after bottling using a modified solid-phase microextraction gas chromatography-mass spectrometry method (SPE-SPME-GC-MS) as described by Nauer et al. [34].

\section{Sensory}

The sensory evaluation was conducted with a trained panel of 6 people and was performed 10 months after bottling. Wines were cooled to $9{ }^{\circ} \mathrm{C}$ and served at ambient temperature. During a preliminary sensory evaluation, the repetitions of each treatment were compared to verify possible variations. Repetitions of each treatment, which indicated no differences, were combined and used for the main sensory evaluation. Thereby, panellists described and evaluated each sample in two repetitions. To assess the sensory quality, international approved 20 point scheme and additionally descriptive free-choice analysis were implemented.

\section{Statistics}

Each pretreatment was repeated three times; chemical and physical analysis of each pretreatment were at least done in triplicates. Statistical tests were performed with Statgraphics Centurion XVIII (Statpoint Technologies, Virginia, USA). The plotted results are presented as mean value \pm SD. The significance level for analyses of variance (ANOVA) was set to $p<0.05$. LSD post hoc comparison testing was used to identify significant differences of means.

\section{Results and discussion}

\section{Juice yield}

The results in Fig. 1 describe the influence of PEF and enzymatic mash treatment on juice yield of Grüner Veltliner and Traminer in dependency of maceration time and over the course of applied pressing conditions. For both varieties, no relevant differences between the treated (PEF + enzymes) and untreated (only enzymes) mash, independent from the maceration time were detectable. The additional application of PEF pretreatment does not lead to higher overall juice
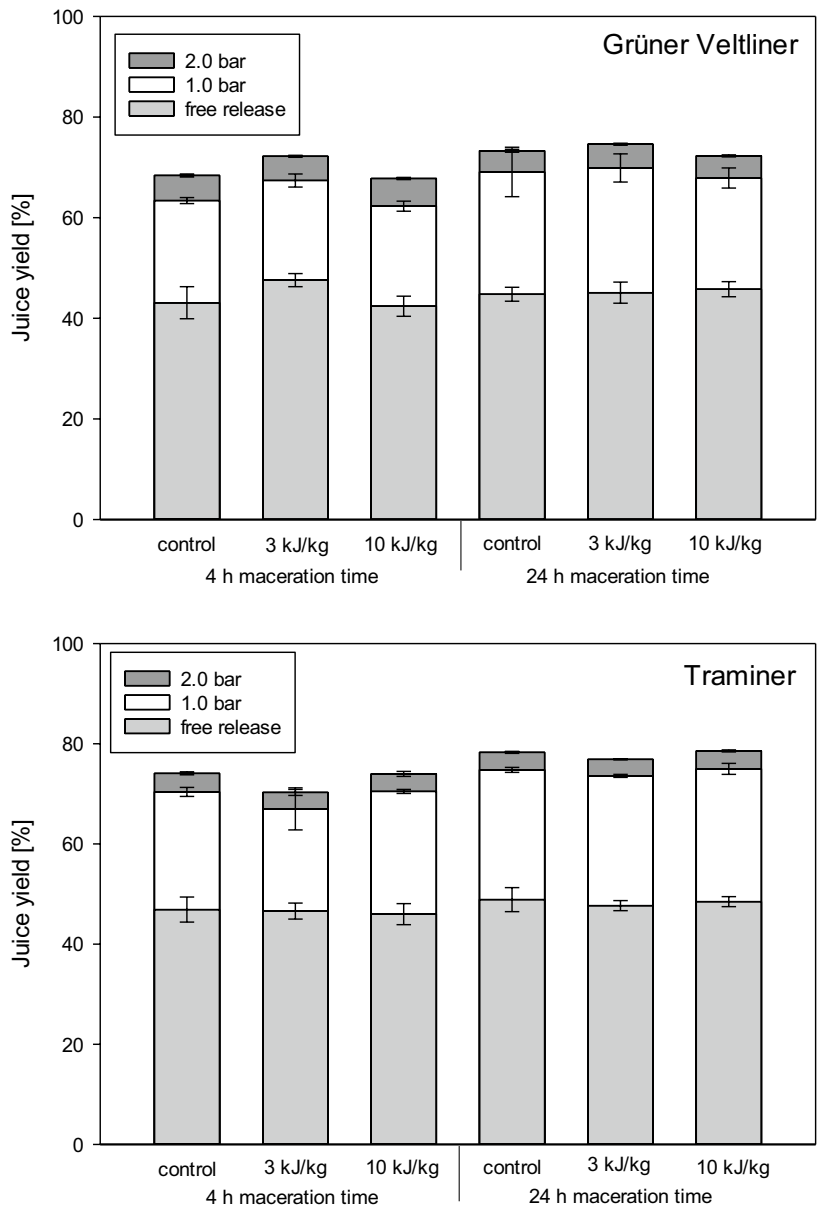

Fig. 1 Dependence of juice yield of Grüner Veltliner and Traminer related to different pressing conditions and PEF intensities obtained from pressing after 4 and $24 \mathrm{~h}$ maceration time with skin contact

yield and does also not show a difference in juice yield for the pressing stages operating at lower pressure. Hence, an adaptation of the pressure profile cannot be considered as a mean to convert the cell permeabilisation achieved by PEF into higher juice yields in this case. The extension of the maceration time was found to contribute to increase the juice yield. However, no effect of PEF was detected for the longer maceration times and the potential benefit of PEF in reducing maceration times could not be found. López et al. [13] studied the vinification of Tempranillo grapes and showed the possibility of reducing the maceration time by applying a PEF treatment. Also, Praporscic et al. [35] determined an increase of juice yield by $\operatorname{PEF}(E=750 \mathrm{~V} / \mathrm{cm}$ $W \approx 20 \mathrm{~kJ} / \mathrm{kg}$ ) for white grapes from $49-54$ to $76-78 \%$, after pressing with constant 5 bar for 45 min. Jaeger et al. [36] describe an increased juice release for carrots $(8-31 \%)$ and apples $(0-11 \%)$ already at lower pressure. Different pressing systems, raw materials and mash structures were used and make direct comparison of results difficult. However, most of the studies detecting an increased juice release by 
the application of electric fields used raw materials without any kind of common pretreatments, such as the addition of enzymes, as control for comparison. Taking into account that enzymatic mash treatment increases the juice release by the degradation of pectin and facilitates the extraction process, its application is crucial to modify the mash structure and viscosity as intended during conventional vinification. Furthermore, the beneficial effect of PEF in comparison to untreated mash related to extraction processes, was described as much more distinct immediately after the pretreatment, and decreases by extended time of skin contact. Whereby the differences can be related to the activity of native and added pectinases and osmotic effects during the fermentation process. Delsart et al. [16] detected that the application of PEF pretreatment with $4 \mathrm{kV} / \mathrm{cm}$ leads to an increase in polyphenols with only $11 \%$ remaining after alcoholic fermentation with skins, whereby the measured concentration in the same must (before fermentation) was $55 \%$ higher compared to untreated grapes. Although, a PEF treatment can contribute to the disintegration of the cell membrane and to the release of intracellular compounds, the impact of conventional processing steps such as the application of enzymes or the alcoholic fermentation with skins, remain relevant to generate desired product properties. Hence, PEF effects are superimposed by the other processing steps and benefits with regard to juice yield increase cannot be maintained.

\section{Fermentation behaviour}

For the wine industry, a rapid fermentation and complete conversion of sugar into alcohol are of main importance for reasons of product quality and process efficiency. The present investigations show that PEF pretreatment reduces the fermentation time to a small extent. In case of the variety Traminer, the duration of the fermentation could be reduced from 16 to 14 days or from 20 to 16 days depending on the maceration time of 4 or $24 \mathrm{~h}$, respectively (Table 1 ). Thereby, the applied energy input during PEF treatment shows no significant effect. However, the fermentation of the variety Grüner Veltliner was not affected by the PEF

Table 1 Duration of fermentation (days) depending on pretreatment, variety and maceration time

\begin{tabular}{lcclc}
\hline Variety & $\begin{array}{l}\text { Maceration } \\
\text { time (h) }\end{array}$ & Control & \multicolumn{2}{l}{$\begin{array}{l}\text { Fermentation time } \\
\text { (days) }\end{array}$} \\
\cline { 3 - 5 } & & & $3 \mathrm{~kJ} / \mathrm{kg}$ & $10 \mathrm{~kJ} / \mathrm{kg}$ \\
\hline Grüner Veltliner & 4 & $31 \pm 1$ & $31 \pm 0$ & $30 \pm 1$ \\
& 24 & $31 \pm 1$ & $31 \pm 1$ & $30 \pm 1$ \\
Traminer & 4 & $16 \pm 0$ & $14 \pm 1$ & $15 \pm 1$ \\
& 24 & $20 \pm 2$ & $16 \pm 1$ & $16 \pm 1$ \\
\hline
\end{tabular}

pretreatment. Independent from the time of skin contact and pretreatment intensity, the alcoholic fermentation lasted approximately 30 days.

The impact of PEF regarding the reduction of fermentation time could be related to the facilitated extraction of nitrogen. The recent investigations show that, especially for Traminer, beside the extended maceration time, also the application of PEF leads to a significantly higher release of total nitrogen (Fig. 2). The content increased by about $10 \%$, whereby no significant differences between both energy inputs were detectable. Previous investigations showed that immediately after PEF pretreatment, the ammonium concentration and the amino acid content of Parellada and Garganega grape juice are not affected in comparison to untreated samples [24, 37]. However, different varieties were investigated and no maceration was applied.

For the alcoholic fermentation, the presence of assimilable nitrogen is of main importance and it is considered as a limiting nutrient for yeasts [38]. Particularly, lower nitrogen content during the fermentation leads to reduced yeast population and increased occurrence of stuck and slow fermentations [39]. Furthermore, the formation of negative volatile sulphur compounds with a characteristic odour of rotten eggs, putrefaction, onion and garlic, undesirable thiols and higher alcohols, is favoured, whereas desirable esters and long chain fatty acids decrease [40, 41].

\section{Turbidity}

The commonly used method for clarification before fermentation is spontaneous settling, whereby pectolytic enzymes are often added for the degradation of pectin and to decrease the processing time [42]. Effects of PEF and enzyme treatment on juice turbidity immediately after pressing measured

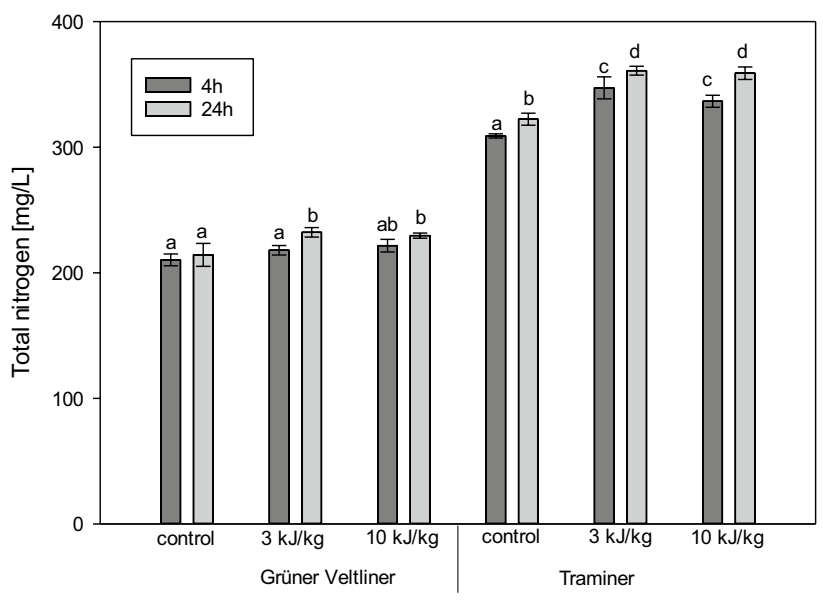

Fig. 2 Total nitrogen content of Grüner Veltliner and Traminer depending on pretreatment and maceration time. Means with different letters per variety are significantly different $(p<0.05)$ 
in the must are shown in Fig. 3. Especially, findings for the variety Traminer indicate a significantly higher degree of turbidity (17\%) after combined PEF and enzyme treatment in comparison to the control for which enzyme treatment only was applied. The increase was not affected by the time of skin contact. In contrast, no distinct effect of PEF was detectable for Grüner Veltliner independent of maceration time and energy input. Higher turbidity and negative effects on sedimentation were also detected after PEF treatment of Garganega grapes [24]. However, investigations from Praporscic et al. [35] showed a decrease of juice turbidity and the content of solid particles after the application of PEF for different white grape varieties. Additionally, Grimi et al. [23] do not note any effects of PEF on the turbidity of white grape juice independent from the applied pressing conditions. Singleton et al. [43] and Koenitz et al. [44] investigated the influence of higher turbidity degrees during fermentation on sensory properties of different white wines. Thereby, an expert panel of tasters described wines prepared from clarified juices are higher in quality and with a more intense aroma than wines fermented with higher amounts of suspended solids. The turbidity leads to increased astringency and bitterness, which was described by the panel as a harsh taste with additional off odours, especially hydrogen sulphide. Lower turbidity during the fermentation limits the release of fusel alcohols, which leads to a typical wine aroma quality [42]. Therefore it is of main importance for the production of high-quality wines to minimize the presence of lees during the fermentation. Due to the increased turbidity achieved by PEF, the clarification process needs to be more efficient which could be realized by adding higher enzyme concentrations and/or an additional clarification step such as separation or filtration systems, both come along with higher production costs and time exposure.

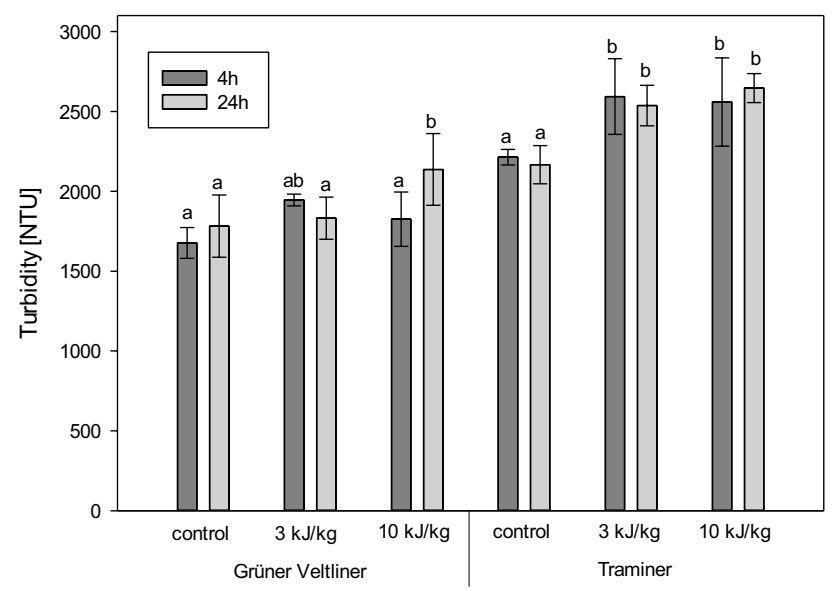

Fig. 3 Dependence of turbidity of Grüner Veltliner and Traminer regarding energy input and maceration time. Means with different letters are significantly different $(p<0.05)$

\section{Impact of PEF and enzyme pretreatment on hydroxycinnamic acids}

In white wine, hydroxycinnamic acids are the main class of polyphenols, whereby caftaric acid, $p$-coutaric acid and fertaric acid are the most important ones. Trans-caftaric acid and trans-fertaric acid are easier to release during pressing due to their presence in the pulp, whereas cis and trans $p$-coutaric acids are localized in the skin and hence less extractable $[45,46]$. In Table 2 , the total polyphenol content (TPC) and the concentration of selected polyphenols especially hydroxycinnamates are shown for Grüner Veltliner and Traminer after 10 months of storage. Almost all analytes increased by the application of PEF are independent from the variety. However, due to PEF, the release of phenols which were localized in the pulp was significantly more affected than phenols from the skin. For Grüner Veltliner, $c$-coutaric acid (skin) was increased by application of PEF $(10 \mathrm{~kJ} / \mathrm{kg})$ and enzymes of about $23 \%$ whereas trans-caftaric acid (pulp) showed an increase of $96 \%$, in comparison to the sample pretreated by enzymes only.

The facilitated extraction of phenols from red grapes due to PEF is described as a major positive effect due to the resulting enhanced intensity of colour and mouth feeling [47]. The application of PEF on Merlot grapes resulted in an increased release of selective phenols and additionally improved the sensory attributes. Additionally, the enhanced release of total phenols was described in previous literature as a potential health benefit $[3,48]$.

However, in the case of white wine, increased polyphenol contents often lead to higher astringency, bitterness and accelerated ageing [8]. The present results showed that the negative effect of the applied pretreatment regarding the increased polyphenol content is significantly higher for both varieties after $24 \mathrm{~h}$ of maceration. Enhancement of the energy input from 3 to $10 \mathrm{~kJ} / \mathrm{kg}$ only leads to an increase of approximately $10 \%$ of $t$-coutaric acid for Grüner Veltliner after $24 \mathrm{~h}$ whereas the extension of maceration time from 4 to $24 \mathrm{~h}$ (at $10 \mathrm{~kJ} / \mathrm{kg}$ ), resulted in an increase of $32 \%$. In addition, an increase of the specific energy input did not lead to a higher release of polyphenols in general. As already described for red grape skins, the impact of the applied PEF intensity on the extraction of polyphenols, anthocyanins and colour intensity depended on the grape variety and the initial composition. Increasing the field strength from 2 to $10 \mathrm{kV} / \mathrm{cm}$ leads to a significant improvement for Mazuelo, whereas it did not show improvements for Garnacha and Graciano [19, 20]. Therefore, in case of implementation for industrial use, it is essential to define an appropriate combination of the PEF parameters and the time of maceration in dependency of the variety. 


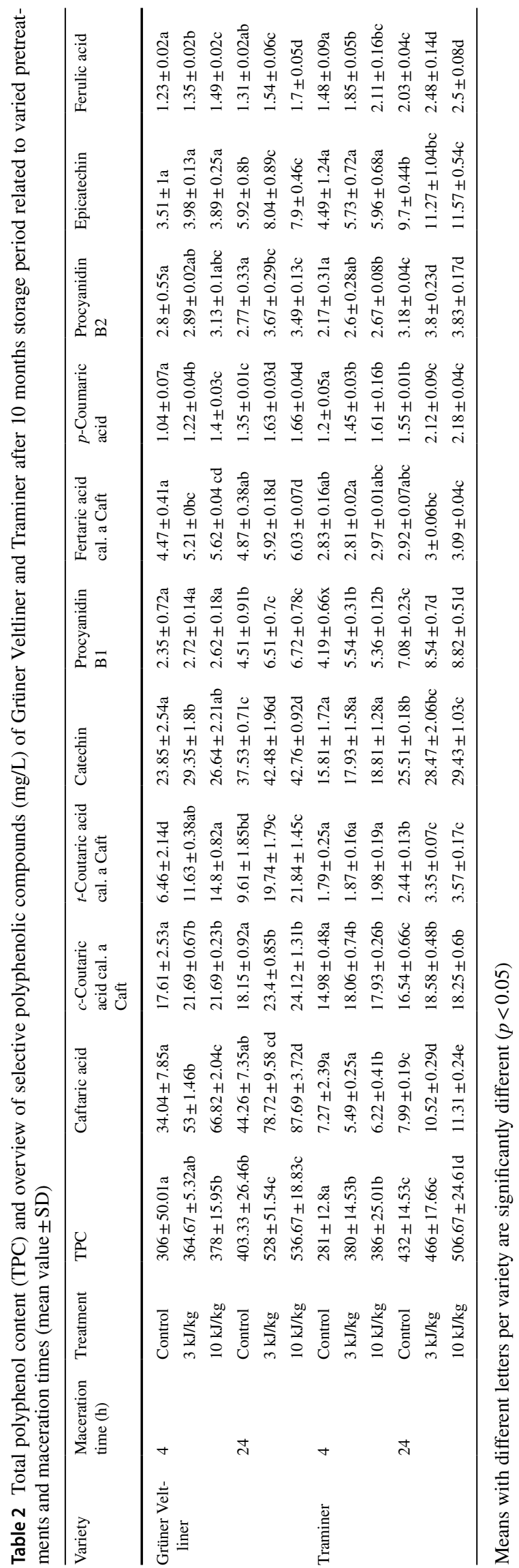

\section{Volatile compounds and sensory evaluation}

The olfactory attributes of wine are related to more than 800 volatile compounds, whereby some are already present in the grapes, some are formed during the alcoholic fermentation and others are developed during ageing [49]. The different odoriferous compounds are located both in the skin and in the pulp, whereby their distribution depends on the variety [50]. The usage of enzymes during the maceration time results in significant higher contents of free terpenes and norisoprenoids as compared to the application of clarification enzymes, which is due to the additional glycosidase activity of maceration enzymes [51].

In general, the aroma composition of the variety Grüner Veltliner was not significantly affected by the combined application of PEF and enzymes. Almost all tested esters (Table 3) and terpenes (Table 4) indicated low levels and no differences due to the PEF treatments at different intensities were detectable. Only the esters, ethyl butyrate and acetic acid-2 and 3-methylbutyl ester were enhanced by the PEF treatment. In addition, the extension of the maceration time did not result in an increased concentration of esters. For the specific "peppery" character of the variety Grüner Veltliner, the sesquiterpene rotundone is responsible. Approximately $99 \%$ of the total rotundone of Grüner Veltliner is placed in the exocarp [52]. In light of this fact, extended skin contact is able to increase the release of this specific sesquiterpene. In the present study, the content of rotundone for the variety Grüner Veltliner was not positively affected neither by the applied PEF pretreatment nor by extending the maceration time from 4 to $24 \mathrm{~h}$ (Fig. 4). This can be explained by the comparably low amount of the sesquiterpene measured in the wine of only $11 \mathrm{ng} / \mathrm{L}$, which is related to the used variety clone, climate and vintage. The concentrations of rotundone of Austrian Grüner Veltliner can range from 9.5 to $84.7 \mathrm{ng} / \mathrm{L}$ [34]. For the investigated conditions, no benefit from the application of PEF or extended maceration could be derived.

As already mentioned and described for polyphenols, the effect of pretreatments with electric fields on volatile compounds also depends on the variety. Garde-Cerdán et al. [15] described an enhanced amount of monoterpenoids, $\beta$-ionone, total esters and benzenoid compounds for Grenache, whereas the quantity of volatile components of Tempranillo and Graciano was not increased by PEF pretreatment. Differences depending on variety were also found in the present study, where the effects of a PEF pretreatment were significantly higher for Traminer compared to Grüner Veltliner. By the application of $10 \mathrm{~kJ} / \mathrm{kg}$ and $24 \mathrm{~h}$ maceration time, the concentration of selective esters such as ethyl-trans-2-decenoate $(+150 \%)$, ethyl dodecanoate $(+110 \%)$ and ethyl decanoate $(+87 \%)$ got significantly increased compared to the samples treated by enzymes only. For all selected terpenes, a significant increase for PEF treated grapes $(3 \mathrm{~kJ} / \mathrm{kg})$ compared 


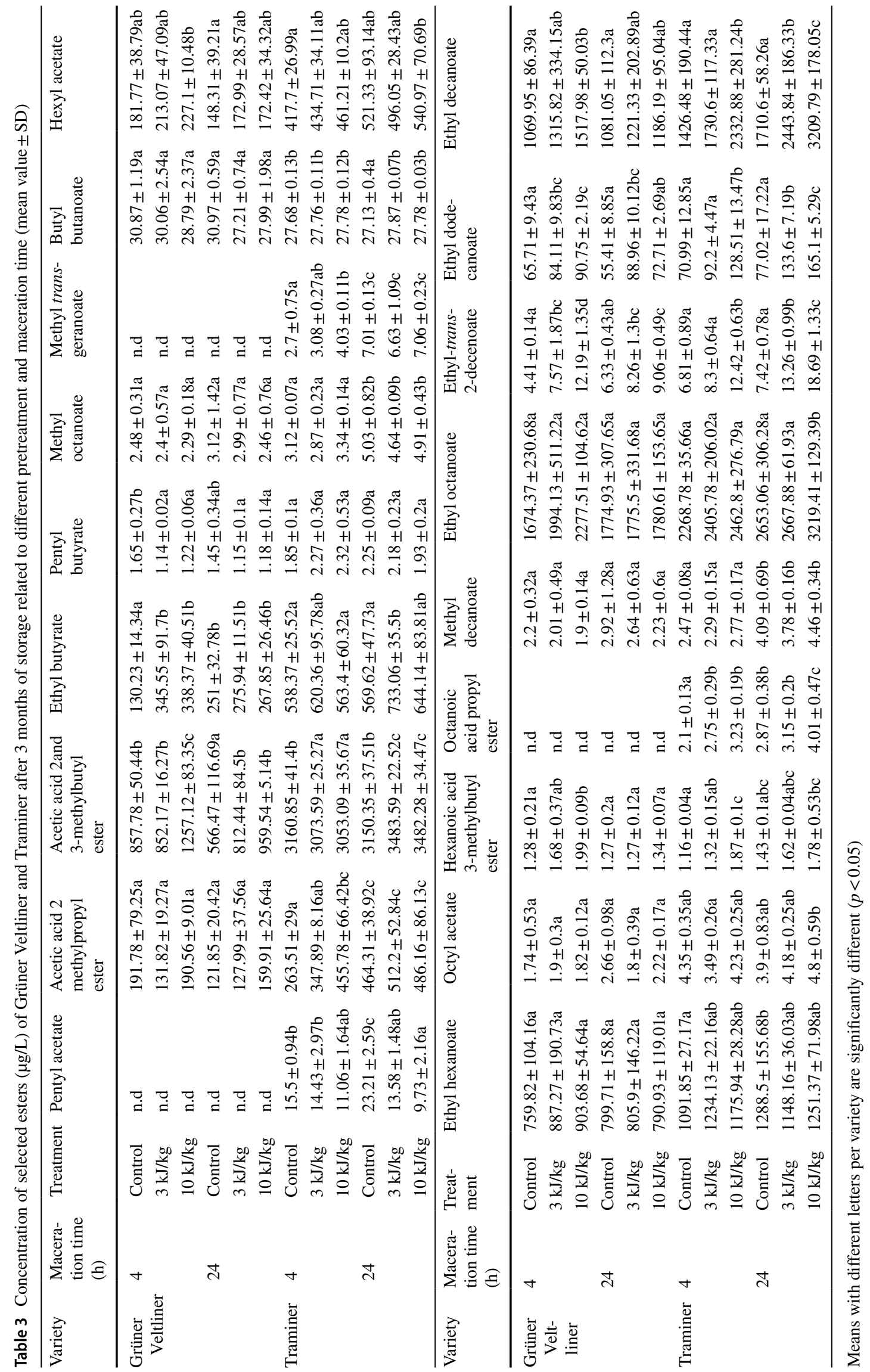




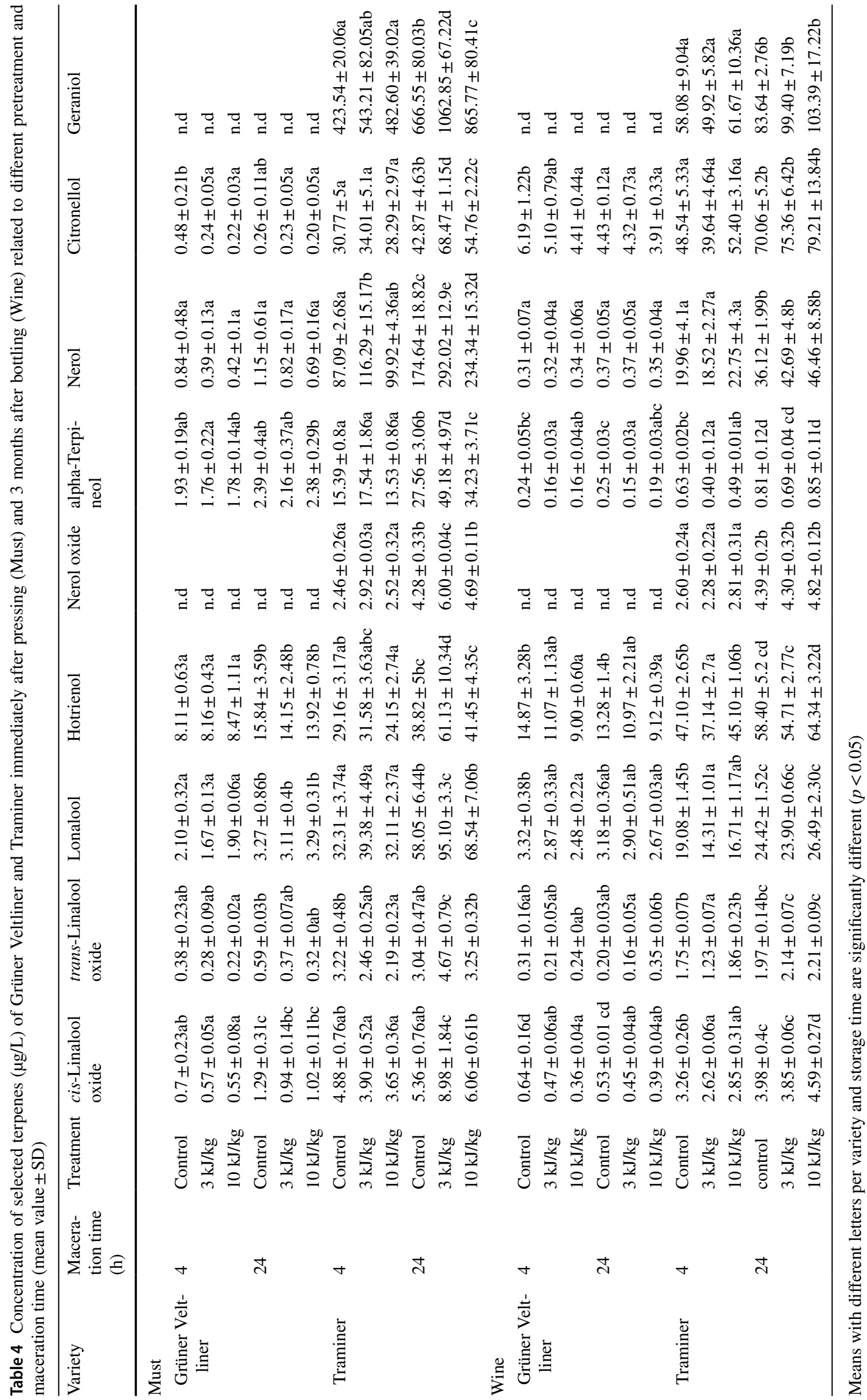




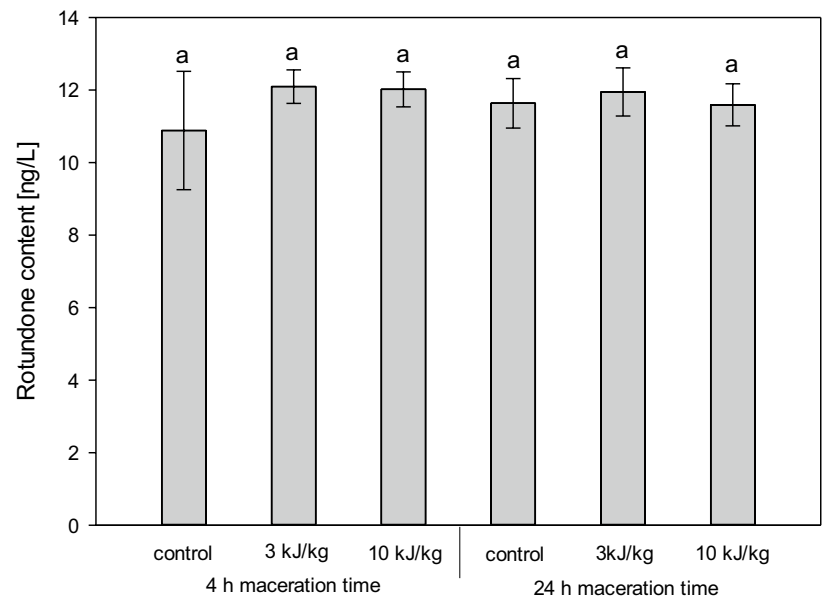

Fig. 4 Content of the sesquiterpene rotundone of Grüner Veltliner in dependency of the applied pretreatment and maceration time. Means with different letters are significantly different $(p<0.05)$

to the enzyme treated control was found immediately after pressing performed after $24 \mathrm{~h}$ maceration time. However, the beneficial effect of PEF was not detectable anymore 3 months after bottling. Moio et al. [42] already described that during the fermentation process, volatile compounds such as bound geraniol, benzyl alcohol and 2 phenylethanol significantly decrease and in some cases free forms of linalool and benzyl alcohol increase by fermentation.

Moreover, the sensory panel detected no significant differences between the tested pretreatments based on the 20 point scheme. All samples originating from the same variety were described by the same values (results are not shown). Furthermore, the evaluation of the descriptive analysis did not result in any specific assignments of sensory attributes. Hence, although relevant volatile compounds especially of the variety Traminer got increased by the application of PEF, the sensory evaluation did not show detectable benefits related to the olfactory character of the wine.

These results are also in correspondence with the findings from Puértolas et al. [11]. They detected a positive impact of PEF on colour intensity, anthocyanin content, total polyphenol and tannin content of Cabernet Sauvignon. However, sensory assessment after 4 months bottle ageing resulted in similar results for the pretreated and control wines.

\section{Conclusion}

The present study shows that selected primary aroma compounds, which are mainly located in the mesocarp, can be extracted more efficiently due to the increased cell permeabilisation, based on a PEF pretreatment. In contrast to previous works, no beneficial effects of PEF on juice yield were detectable for the given experimental setup considering the use of conventional pectolytic enzymes and the applied pressing system. The PEF induced increase of released nitrogen can lead to a reduction of the mean fermentation time of up to $20 \%$ depending on the variety. The release of compounds associated to the skin, such as rotundone, were not affected by the application of PEF. Furthermore, adverse outcomes of the PEF treatment were identified related to the increase of turbidity and the higher amount of polyphenols which are undesired effects especially for white wine. However, it was detectable that the advantages of PEF in combination with the application of maceration enzymes significantly depends on the processed variety. Especially for the production of wines with specific aroma profiles, such as Traminer and Muscat, the application of electric fields is very promising. To conclude on the benefits from the use of PEF for white wine production, further varieties and processing parameters at the different steps of the vinification process need to be investigated.

Acknowledgements Open access funding provided by University of Natural Resources and Life Sciences Vienna (BOKU). The authors would like to thank the Federal College and Research Institute for Viticulture and Pomology in Klosterneuburg for the deployment of the raw material and the supply of the oenological equipment. Furthermore, special thanks to Martin Prinz, Stefan Nauer and their teams for the analytical support and advice.

\section{Compliance with ethical standards}

Conflict of interest The authors declare that they have no conflict of interest.

Compliance with ethical requirements This article does not contain any studies with human or animal subjects.

Open Access This article is licensed under a Creative Commons Attribution 4.0 International License, which permits use, sharing, adaptation, distribution and reproduction in any medium or format, as long as you give appropriate credit to the original author(s) and the source, provide a link to the Creative Commons licence, and indicate if changes were made. The images or other third party material in this article are included in the article's Creative Commons licence, unless indicated otherwise in a credit line to the material. If material is not included in the article's Creative Commons licence and your intended use is not permitted by statutory regulation or exceeds the permitted use, you will need to obtain permission directly from the copyright holder. To view a copy of this licence, visit http://creativecommons.org/licenses/by/4.0/.

\section{References}

1. Amrani-Joutei K, Glories Y (1995) Tannins and anthocyanins of grape berries: localization and extraction technique. Revue Francaise d'Oenologie 153:28-31

2. Sacchi KL, Bisson LF, Adams DO (2005) A review of the effect of winemaking techniques on phenolic extraction in red wines. Am J Enol Vitic 56(3):197-206 
3. Darias-Martín JJ, Rodríguez O, Díaz E, Lamuela-Raventós RM (2000) Effect of skin contact on the antioxidant phenolics in white wine. Food Chem 71(4):483-487

4. Ganga A, Piñaga F, Querol A, Vallés S, Ramón D (2001) Cell-wall degrading enzymes in the release of grape aroma precursors. Food Sci Technol Int 7(1):83-87

5. Rocha SM, Coutinho P, Delgadillo I, Cardoso AD, Coimbra MA (2005) Effect of enzymatic aroma release on the volatile compounds of white wines presenting different aroma potentials. J Sci Food Agric 85(2):199-205

6. Donèche B (1993) Les acquisitions récentes en chromatographie du vin: applications à l'analyse sensorielle des vins. Tec \& Doc Distribution

7. Palomo ES, Pérez-Coello M, Díaz-Maroto M, Viñas MG, Cabezudo M (2006) Contribution of free and glycosidically-bound volatile compounds to the aroma of muscat "a petit grains" wines and effect of skin contact. Food Chem 95(2):279-289

8. Sokolowsky M, Rosenberger A, Fischer U (2015) Sensory impact of skin contact on white wines characterized by descriptive analysis, time-intensity analysis and temporal dominance of sensations analysis. Food Qual Prefer 39:285-297. https://doi.org/10.1016/j. foodqual.2014.07.002

9. Wenzel K, Dittrich H (1978) Zur Beeinflussung der Schwefelwasserstoff-Bildung der Hefe durch Trub, Stickstoffgehalt, molekularen Schwefel und Kupfer bei der Vergarung von Traubenmost. Wein-Wissenschaft

10. Mannozzi C, Fauster T, Haas K, Tylewicz U, Romani S, Dalla Rosa M, Jaeger H (2018) Role of thermal and electric field effects during the pre-treatment of fruit and vegetable mash by pulsed electric fields $(\mathrm{PEF})$ and ohmic heating $(\mathrm{OH})$. Innov Food Sci Emerg Technol 48:131-137. https://doi.org/10.1016/j.ifset 2018.06.004

11. Puértolas E, Hernández-Orte P, Sladaña G, Álvarez I, Raso J (2010) Improvement of winemaking process using pulsed electric fields at pilot-plant scale. Evolution of chromatic parameters and phenolic content of Cabernet Sauvignon red wines. Food Res Int 43(3):761-766. https://doi.org/10.1016/j.foodres.2009.11.005

12. Lebovka NI, Shynkaryk MV, El-Belghiti K, Benjelloun H, Vorobiev E (2007) Plasmolysis of sugarbeet: Pulsed electric fields and thermal treatment. J Food Eng 80(2):639-644. https://doi. org/10.1016/j.jfoodeng.2006.06.020

13. López N, Puértolas E, Condón S, Álvarez I, Raso J (2008) Effects of pulsed electric fields on the extraction of phenolic compounds during the fermentation of must of Tempranillo grapes. Innov Food Sci Emerg Technol 9(4):477-482. https://doi.org/10.1016/j. ifset.2007.11.001

14. Donsì F, Ferrari G, Fruilo M, Pataro G (2010) Pulsed electric field-assisted vinification of Aglianico and Piedirosso grapes. J Agric Food Chem 58(22):11606-11615

15. Garde-Cerdán T, González-Arenzana L, López N, López R, Santamaría P, López-Alfaro I (2013) Effect of different pulsed electric field treatments on the volatile composition of Graciano, Tempranillo and Grenache grape varieties. Innov Food Sci Emerg Technol 20:91-99. https://doi.org/10.1016/j.ifset.2013.08.008

16. Delsart C, Cholet C, Ghidossi R, Grimi N, Gontier E, Gény L, Vorobiev E, Mietton-Peuchot M (2014) Effects of pulsed electric fields on Cabernet Sauvignon grape berries and on the characteristics of wines. Food Bioprocess Technol 2(7):424-436

17. Lebovka NI, Praporscic I, Vorobiev E (2003) Enhanced expression of juice from soft vegetable tissues by pulsed electric fields: consolidation stages analysis. J Food Eng 59(2-3):309-317

18. Boussetta N, Lebovka N, Vorobiev E, Adenier H, Bedel-Cloutour C, Lanoiselle J-L (2009) Electrically assisted extraction of soluble matter from chardonnay grape skins for polyphenol recovery. $\mathrm{J}$ Agric Food Chem 57(4):1491-1497
19. López N, Puértolas E, Condón S, Álvarez I, Raso J (2008) Application of pulsed electric fields for improving the maceration process during vinification of red wine: influence of grape variety. Eur Food Res Technol 227(4):1099. https://doi.org/10.1007/s0021 7-008-0825-y

20. López-Giral N, González-Arenzana L, González-Ferrero C, López R, Santamaría P, López-Alfaro I, Garde-Cerdán T (2015) Pulsed electric field treatment to improve the phenolic compound extraction from Graciano, Tempranillo and Grenache grape varieties during two vintages. Innov Food Sci Emerg Technol 28:31-39. https://doi.org/10.1016/j.ifset.2015.01.003

21. Donsì F, Ferrari G, Fruilo M, Pataro G (2011) Pulsed electric fields-assisted vinification. Proc Food Science 1:780-785. https ://doi.org/10.1016/j.profoo.2011.09.118

22. Puértolas E, Saldaña G, Condón S, Álvarez I, Raso J (2009) A comparison of the effect of macerating enzymes and pulsed electric fields technology on phenolic content and color of red wine. J Food Sci 74(9):C647-C652

23. Grimi N, Lebovka NI, Vorobiev E, Vaxelaire J (2009) Effect of a pulsed electric field treatment on expression behavior and juice quality of Chardonnay grape. Food Biophys 4(3):191-198. https ://doi.org/10.1007/s11483-009-9117-8

24. Comuzzo P, Marconi M, Zanella G, Querzè M (2018) Pulsed electric field processing of white grapes (cv. Garganega): effects on wine composition and volatile compounds. Food Chem 264:1623. https://doi.org/10.1016/j.foodchem.2018.04.116

25. Meneses N, Jaeger H, Moritz J, Knorr D (2011) Impact of insulator shape, flow rate and electrical parameters on inactivation of E. coli using a continuous co-linear PEF system. Innov Food Sci Emerg Technol 12(1):6-12

26. Ancín C, Ayestarán B, Corroza M, Garrido J, González A (1996) Influence of prefermentation clarification on the higher alcohol contents of wines. Food Chem 55(3):241-249

27. Singleton VL, Orthofer R, Lamuela-Raventós RM (1999) [14] Analysis of total phenols and other oxidation substrates and antioxidants by means of folin-ciocalteu reagent. Methods Enzymol 299:152-178

28. Vrhovšek U (1998) Extraction of hydroxycinnamoyltartaric acids from berries of different grape varieties. J Agric Food Chem 46(10):4203-4208

29. Eder R, Regner F, Goll A (2013) Phenol composition, antioxidative capacity and need of $\mathrm{SO}_{2}$ of some PIWI cultivars. Mitteilungen Klosterneuburg 63:46-47

30. Liszt KI, Eder R, Wendelin S, Somoza V (2015) Identification of catechin, syringic acid, and procyanidin $\mathrm{B} 2$ in wine as stimulants of gastric acid secretion. J Agric Food Chem 63(35):7775-7783

31. Philipp C, Nauer S, Sari S, Eder P, Patzl-Fischerleitner E, Eder R (2019) Quantification of 38 volatile ester compounds by means of SIDA-HS-SPME-GC-MS in 'Pinot blanc' wines and comparison with other important Austrian varieties. Mitteilungen Klosterneuburg 69:93-114

32. Philipp C, Eder P, Brandes W, Patzl-Fischerleitner E, Eder R (2018) The pear aroma in the Austrian Pinot blanc wine variety: evaluation by means of sensorial-analytical-typograms with regard to vintage, wine styles, and origin of wines. J Food Qual 2018:1-12

33. Michlmayr H, Nauer S, Brandes W, Schümann C, Kulbe KD, del Hierro AM, Eder R (2012) Release of wine monoterpenes from natural precursors by glycosidases from Oenococcus oeni. Food Chem 135(1):80-87. https://doi.org/10.1016/j.foodc hem.2012.04.099

34. Nauer S, Brandes W, Patzl-Fischerleitner E, Hann S, Eder R (2018) Analysis of (-)-rotundone by means of SPE-SPME-GCMS in Austrian quality wines of the' Grüner Veltliner'variety. Mitteilungen Klosterneuburg 68(2):107-119 
35. Praporscic I, Lebovka N, Vorobiev E, Mietton-Peuchot M (2007) Pulsed electric field enhanced expression and juice quality of white grapes. Sep Purif Technol 52(3):520-526. https://doi. org/10.1016/j.seppur.2006.06.007

36. Jaeger H, Schulz M, Lu P, Knorr D (2012) Adjustment of milling, mash electroporation and pressing for the development of a PEF assisted juice production in industrial scale. Innov Food Sci Emerg Technol 14:46-60. https://doi.org/10.1016/j.ifset .2011 .11 .008

37. Garde-Cerdán T, Arias-Gil M, Marsellés-Fontanet AR, AncínAzpilicueta C, Martín-Belloso O (2007) Effects of thermal and non-thermal processing treatments on fatty acids and free amino acids of grape juice. Food Control 18(5):473-479. https://doi. org/10.1016/j.foodcont.2005.12.004

38. Bely M, Sablayrolles J-M, Barre P (1990) Automatic detection of assimilable nitrogen deficiencies during alcoholic fermentation in oenological conditions. J Ferment Bioeng 70(4):246-252

39. Beltran G, Esteve-Zarzoso B, Rozès N, Mas A, Guillamón JM (2005) Influence of the timing of nitrogen additions during synthetic grape must fermentations on fermentation kinetics and nitrogen consumption. J Agric Food Chem 53(4):996-1002

40. Mestres M, Busto O, Guasch J (2000) Analysis of organic sulfur compounds in wine aroma. J Chromatogr A 881(1-2):569-581

41. Bell SJ, Henschke PA (2005) Implications of nitrogen nutrition for grapes, fermentation and wine. Aust J Grape Wine Res 11(3):242-295

42. Moio L, Ugliano M, Gambuti A, Genovese A, Piombino P (2004) Influence of clarification treatment on concentrations of selected free varietal aroma compounds and glycoconjugates in Falanghina (Vitis vinifera L.) must and wine. Am J Enol Vitic 55(1):7-12

43. Singleton V, Sieberhagen H, De Wet P, Van Wyk C (1975) Composition and sensory qualities of wines prepared from white grapes by fermentation with and without grape solids. Am J Enol Vitic 26(2):62-69

44. Koenitz R, Freund M, Seckler J, Christmann M, Netzel M, Strass G, Bitsch I, Bitsch R (2003) Einfluss der Mostvorklärung auf die sensorische Qualität von Rieslingweinen aus dem Rheingau. Mitteilungen Klosterneuburg 53:177-194
45. Waterhouse AL (2002) Wine phenolics. Ann N Y Acad Sci 957(1):21-36

46. Garrido J, Borges F (2013) Wine and grape polyphenols-a chemical perspective. Food Res Int 54(2):1844-1858. https://doi. org/10.1016/j.foodres.2013.08.002

47. Yang N, Huang K, Lyu C, Wang J (2016) Pulsed electric field technology in the manufacturing processes of wine, beer, and rice wine: a review. Food Control 61:28-38. https://doi.org/10.1016/j. foodcont.2015.09.022

48. Lippi G, Franchini M, Favaloro EJ, Targher G (2010) Moderate red wine consumption and cardiovascular disease risk: beyond the "French paradox". In: Seminars in thrombosis and hemostasis, vol 01. (C) Thieme Medical Publishers, pp 059-070

49. Câmara JdS, Alves MA, Marques JC (2006) Changes in volatile composition of Madeira wines during their oxidative ageing. Anal Chim Acta 563(1-2):188-197

50. Perestrelo R, Barros AS, Rocha SM, Câmara JS (2011) Optimisation of solid-phase microextraction combined with gas chromatography-mass spectrometry based methodology to establish the global volatile signature in pulp and skin of Vitis vinifera $\mathrm{L}$. grape varieties. Talanta 85(3):1483-1493. https://doi.org/10.1016/j.talan ta.2011.06.025

51. Armada L, Fernández E, Falqué E (2010) Influence of several enzymatic treatments on aromatic composition of white wines. LWT Food Sci Technol 43(10):1517-1525. https://doi. org/10.1016/j.1wt.2010.06.009

52. Caputi L, Carlin S, Ghiglieno I, Stefanini M, Valenti L, Vrhovsek U, Mattivi F (2011) Relationship of changes in rotundone content during grape ripening and winemaking to manipulation of the 'peppery' character of wine. J Agric Food Chem 59(10):5565-5571

Publisher's Note Springer Nature remains neutral with regard to jurisdictional claims in published maps and institutional affiliations. 